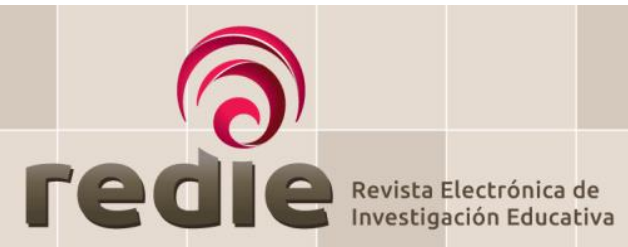

ISSN: $1607-4041$

https://redie.uabc.mx

Vol. 23, 2021/e3r

\title{
El bienestar tecnológico: la relevancia de la educación en la propaganda de la era digital
}

María Eulalia Torras Virgili (*) https://orcid.org/0000-0002-9996-113X

(*) Universidad Internacional de La Rioja

Cómo citar: Torras, M. E. (2021). El bienestar tecnológico: la relevancia de la educación en la propaganda de la era digital. Revista Electrónica de Investigación Educativa, 23, e3r, 1-3. https://doi.org/10.24320/redie.2021.23.e3r.5008

Hobbs, R. (2021). Mind over media propaganda education for a digital age. Norton Books in Education.

El desarrollo integral del alumno considerando las dimensiones cognitiva, afectiva y social es fundamental en el proceso de enseñanza-aprendizaje. Al mismo tiempo, en la era de la inteligencia artificial la competencia digital es clave para que los alumnos sean capaces de adaptarse a la comunidad y al mundo global. Establece y mantener una relación saludable con la tecnología se evidencia ya como una necesidad. En este contexto emerge el concepto de bienestar digital, que se asocia con minimizar los retos y potenciar las ventajas de las TIC en todos los ámbitos de la vida. Este tipo de bienestar supone buscar un equilibrio en la vida digital que favorezca la calidad del tiempo en línea y evite las distracciones producidas por las comunicaciones en momentos no oportunos.

La primera clave para alcanzar el bienestar digital es ser consciente del uso que cada alumno hace de la tecnología para identificar si ésta es fuente de estrés y ansiedad o facilita las comunicaciones significativas. En este proceso de reflexión necesario en las aulas, las fake news (noticias falsas), las cheapfakes (difusión de rumores), los deapfakes (manipulaciones), los memes (mensajes distribuidos viralmente) o los videos que incitan al odio, deben ser analizados desde el pensamiento crítico como una vía para alcanzar el bienestar digital y el desarrollo integral del alumnado.

Fake news, cheapfakes, deapfakes y memes o videos que incitan al odio son considerados propaganda, la cual es un constructo que emerge con un nuevo significado, vinculado a la producción de contenido digital ligado a la fórmula clásica de sensacionalismo utilizando la divulgación viral en Internet. La propaganda está constituida por mensajes vinculados a palabras o a imágenes emocionalmente intensos cuya comunicación se expande a amplias audiencias. Las emociones son consideradas, desde este punto de vista, como herramientas para atraer la atención más que por su valor adaptativo a la sociedad.

En Mind over media propaganda education for a digital age, Renne Hobbs presenta una perspectiva reflexiva sobre este nuevo significado de la propaganda, sus características y tipos, así como propuestas educativas para trabajar en el aula con la finalidad de alcanzar un desarrollo íntegro del alumnado desde el punto de vista cognitivo, emocional y social. El libro responde a preguntas como qué riesgos comporta para el alumnado la exposición amplia a la propaganda en la era digital, cómo crear condiciones en las que el alumnado desarrolle criterios y pensamiento crítico para hacer frente a estos mensajes, cómo crear una experiencia educativa participativa y profunda vinculada al buen uso de las redes sociales para divulgar mensajes de forma viral, y qué actividades son adecuadas para abordar la reflexión sobre la propaganda clave en el desarrollo de la competencia digital del alumnado. 
Hoobs, una autoridad en la comunicación digital y en la educación mediática, es profesora en la Universidad de Rhode Island y desarrolladora de programas educativos desde su labor en Media Education Lab, estructura la monografía en siete capítulos.

El primer capítulo sitúa el concepto de propaganda en la sociedad de la inteligencia artificial, marcada por el Big Data, y ofrece ejemplos de distintas disciplinas -entre las que destaca la educación, el consumo, la política, el arte o los activismos. Estos ejemplos ayudan al lector a visualizar la importancia actual de las comunicaciones virales claramente orientadas a promover una representación mental distorsionada y parcial de la realidad. La fórmula habitual de la propaganda en la era digital es la repetición sostenida (hasta que el receptor acepta como cierto un mensaje), la asociación a partir de un enlace persuasivo con un producto o una persona deseable o temible y la composición a partir de patrones que atraigan la atención de la audiencia. Los ejemplos son adecuados para profesores, pero también para que profesionales de la educación, que desarrollan una función de liderazgo, puedan utilizar el conocimiento de la propaganda para contribuir a que el alumnado evidencie el pensamiento crítico y las habilidades de comunicación desde la responsabilidad y desde una sociedad conectada.

El segundo capítulo analiza el uso de la propaganda en la Educación, para ello revisa prácticas instruccionales que facilitan el desarrollo de la competencia de alfabetización mediática: los diarios mediáticos, las actividades de búsqueda e indagación, las lecturas debatidas, el análisis cerrado, la comparación de mensajes, el contraste de mensajes, las simulaciones, el role-playing y la creación de productos mediáticos son algunos de los ejemplos. El aprendizaje sobre las comunicaciones mediáticas implica la reflexión del alumnado con relación a su posicionamiento ante una comunidad donde la influencia mutua se genera. Contribuir a que el alumnado desarrolle resiliencia a la propaganda es fundamental en la alfabetización digital: la inteligencia artificial implica, a menudo, un uso del Big Data basado en la perspectiva de la persona como consumidor. La importancia del marco, entendida como el lenguaje, la elección del contenido y la organización de las ideas se destaca en este capítulo como una vía para estructurar las interpretaciones de las personas, los eventos y las experiencias.

El tercer capítulo ofrece una visión profunda de la importancia de la economía de la propaganda: enfatiza cómo el modelo de negocio basado en la propaganda ocupa un lugar destacado en la sociedad. Es conveniente que el alumnado identifique distintas formas de advertir que este modelo forma parte de su vida diaria apreciando la forma en que los likes o los mensajes compartidos tienen valor en la economía del mercado mediático. Las claves de la propaganda son, hasta cierto punto, simples: activar emociones fuertes, como el amor, la frustración, la rabia o el miedo; simplificar la información y las ideas, responder a una audiencia a partir de sus necesidades y sus valores y atacar a los oponentes. La publicidad es el motor de la industria mediática, por lo que es fundamental que el alumnado entienda el modelo de negocio que lleva a la propaganda a situarse como relevante en la sociedad.

El cuarto capítulo ofrece sugerencias para que los profesores sean capaces de utilizar estrategias que despolaricen el aula a partir de establecer reglas de comunicación responsable que reflejen los valores, la empatía y el reconociendo de los compañeros, más allá de las posturas. Dar a conocer claves que permiten al alumnado diferenciar entre noticias rigurosas y fake news, cheapfakes, deapfakes, memes o videos con información falsa es útil. Así, la identificación de noticias con contenido patrocinado, noticias partidistas, teorías de la conspiración y pseudociencias, parodias, sátiras, memes o bots (programas informáticos) deben ser conocidos por el alumnado para poder identificar fuentes de influencia cuya intencionalidad es la manipulación a partir de ofrecer información incompleta y distorsionada. Incluso, a partir de la adolescencia, las actividades pueden permitir a los estudiantes una reflexión sobre su propio posicionamiento con relación a cuestiones ideológicas, de modo que el proceso contribuye a la construcción de la identidad del alumno.

El quinto capítulo se centra en las consecuencias negativas de la propaganda. En este capítulo el lector encontrará ejemplos de desinformación, intolerancia, incitación al odio, discursos de ira y teorías de la conspiración que han surgido en distintas comunidades. Es importante que los docentes valoren el uso de estos ejemplos, en función de la edad del alumnado y los objetivos de las planificaciones educativas, para disponer de oportunidades de exploración de contenido y actividades de debate en el aula: seleccionando 
aquellos ejemplos más cercanos al propio contexto educativo el profesor podrá dar valor a estas experiencias dentro del marco del proceso de enseñanza-aprendizaje. Conceptos como la despersonalización, la polarización, la conspiración o el descrédito pueden ser analizados y compartidos por el alumnado al relacionar la propaganda con las consecuencias nocivas para las personas. Las actividades permiten explorar la retórica de la supremacía siendo especialmente útiles para ser aplicadas en la prevención del cyberbulling. La descripción del discurso del odio también permite estructurar procesos de enseñanza-aprendizaje ligados a la identificación de este tipo de narraciones desde diversas perspectivas.

El capítulo sexto profundiza en las bondades de la propaganda beneficiosa que puede ser utilizada en disciplinas como el arte o el activismo. El uso de la propaganda para buscar consenso en una sociedad democrática puede construir nuevas políticas. En este sentido, es necesario considerar un mensaje mediático como propaganda beneficiosa cuando: el autor lo ha creado con tal finalidad y es evaluado como positivo para el receptor, su familia, su vecindario o comunidad, a la vez que favorece a la humanidad. Por tanto, el contexto social y la interpretación que se realiza del mensaje es definitoria en el momento de establecer si una propaganda es beneficiosa o no. Las actividades presentadas en este capítulo enfatizan el discurso compartido a partir de las 5W (Qué; Quién/Quiénes, Cuándo, Dónde, Por qué, Cómo. En estas actividades el alumnado toma el papel de productor de contenidos de propaganda beneficiosa a partir de la puesta en práctica de distintos pasos (los roles implicados, el diseño en grupo, la creación del grupo, el análisis grupal y la discusión compartida).

Por último, en el capítulo séptimo se considera la idea de que la propaganda está en el ojo del espectador dado que el ocio crea un sentido compartido de comunidad que contribuye a articular los valores. En este capítulo son especialmente interesantes las actividades propuesta para la práctica en el aula, por ejemplo, las planificaciones para trabajar la violencia, la discriminación y la intolerancia en los videojuegos o las propuestas didácticas sobre el discurso de guerra. La ética en la propaganda ocupa un lugar central en el último capítulo puesto que es clave distinguir entre el uso problemático, e incluso inmoral de ésta, y el uso neutro o la perspectiva positiva -siendo la falsedad, la intencionalidad estratégica y el propósito de contribuir a una representación mental distorsionada de la realidad, la clave para distinguir entre ambas. La propaganda comporta una intención deliberada de sustituir un mensaje, de simplificar la ambigüedad de la realidad compleja privando a la sociedad de las creencias y valores de la diversidad.

La extensa lista de referencias ofrece interesantes y actualizadas alternativas que el profesional de la educación agradecerá si desea ampliar el conocimiento o, bien, profundizar en las planificaciones educativas. La consulta de los artículos referenciados, algunos de ellos disponibles en abierto es un buen complemento al trabajo detallado y riguroso -teórica y metodológicamente- que ofrece el libro. El índice temático, editado con atención al detalle, permite una lectura del texto facilitando la búsqueda de los temas de mayor interés, de modo que el lector puede acceder al contenido que pretende abordar en el proceso de enseñanza-aprendizaje sin que sea necesaria la lectura secuencial del texto.

La monografía destaca por la relevancia dada a la indagación, para concretar una forma de aprendizaje que implica un cuidado al desarrollo integral del alumno; las actividades basadas en la reflexión, en la experimentación y en la experiencia educativa significativa permiten llegar al pensamiento crítico y dotar al alumno de competencias para vivir en una sociedad de la inteligencia artificial que, muy a menudo, prioriza la visión de la persona como consumidor. El alcance aplicado del texto, con detalladas actividades para desarrollar con el alumnado, es un apoyo invaluable para el profesional de la educación comprometido con el desarrollo del alumnado y la construcción de su competencia digital. El texto ha sido considerado el libro más relevante sobre propaganda en los últimos años. 